\title{
Article \\ Determination of Concrete Formwork Removal Time Based on Ultrasound Reflection
}

\author{
Nicolas Ospitia ${ }^{1, * \mathbb{O}}$, Rami Jaramani ${ }^{1}$, Olivier Remy ${ }^{2}$ and Dimitrios G. Aggelis ${ }^{1}$ \\ 1 Department Mechanics of Materials and Constructions, Vrije Universiteit Brussel (VUB), Pleinlaan 2, \\ 1050 Brussels, Belgium; rami.jaramani@vub.be (R.J.); dimitrios.aggelis@vub.be (D.G.A.) \\ 2 Leviat a CRH Company, Industrielaan 2, 1740 Ternat, Belgium; Olivier.Remy@leviat.com \\ * Correspondence: nicolas.ospitia.patino@vub.be
}

check for updates

Citation: Ospitia, N.; Jaramani, R.; Remy, O.; Aggelis, D.G.

Determination of Concrete Formwork Removal Time Based on Ultrasound Reflection. Appl. Sci. 2022, 12, 1221. https://doi.org/10.3390/app12031221

Academic Editor: Giuseppe Lacidogna

Received: 16 December 2021

Accepted: 21 January 2022

Published: 24 January 2022

Publisher's Note: MDPI stays neutral with regard to jurisdictional claims in published maps and institutional affiliations.

Copyright: (c) 2022 by the authors. Licensee MDPI, Basel, Switzerland. This article is an open access article distributed under the terms and conditions of the Creative Commons Attribution (CC BY) license (https:// creativecommons.org/licenses/by/ $4.0 /)$.

\begin{abstract}
Concrete is vastly used in construction due to its high compressive strength, and its ease of shaping. Formworks are used to render the desired shape to the material during its change from a liquid to a solid state, until the concrete develops the required strength. Removing the formwork early can cause excessive deformations or even failure; however, postponing removal also has a delaying effect in construction with economic consequences. In practice, the removal of the formworks is based on the development of the compressive strength vs. the self-weight and temporary loads related to the construction. This study aims to monitor the hardening of concrete columns by means of the reflection of ultrasonic waves. As concrete hardens, its mechanical impedance increases influencing the reflection that can be received by one-sided non-invasive measurements. By suitably selecting the stiffness of the ultrasonic buffer material, the moment that the concrete obtains a specific stiffness can be safely determined for the first time. Results demonstrate sensitivity of the technique on real scale formworks, as it can pinpoint the moment in which the formwork can be removed, while numerical simulations help in the understanding of the complicated wave field and validate the methodology.
\end{abstract}

Keywords: concrete; formwork; demolding; reflection; ultrasound; simulation

\section{Introduction}

In construction sites, fresh concrete is cast into formworks where it progressively hardens and gains considerable load-bearing capacity. Failures in the formworks during the construction process as well as failures originating from early removal of the formwork when the concrete has not developed sufficient strength to bear its own weight and to allow for the continuation of the construction can be catastrophic [1,2]. Furthermore, formworks are expensive with their cost being on many occasions of the same order as the concrete $\operatorname{mix}[3]$.

Since concrete should gain a minimum of strength and stiffness, it is obvious that formworks should not be removed before that point. On the other hand, unmolding should not take place unnecessarily late to avoid construction delays and eventually economic consequences. Therefore, innovation in construction points towards time management, safety and reusability of formworks which entails also strong economic benefits. It becomes clear that a methodology to confirm a minimum degree of concrete hardening necessary for the unmolding would benefit construction. The use of a robust and accurate system to monitor concrete in the formworks on construction sites can lead to more economic and safe construction practices. To date, most of the rules and recommendations for the time required for the demolding of formworks are empirical and may not always be accurate [4] Eurocode 2 [5] mentions that the element should be designed with a partial safety factor of 1.5, which means that at the moment of demolding the structural element should have a loading capacity at least $50 \%$ higher than the load that it is subjected to. According to Mehta and Monteiro [6] the formwork should not be removed until the concrete is strong enough to carry its own weight and the imposed construction load. In addition, concrete 
should be sufficiently hard so that the surface is not injured during the formwork removal. In the American recommendations [7] concerning the removal of forms and supports, it is mentioned that the minimum time for formwork removal is normally a function of strength gained over the strength required. In case a strength requirement is not applied, the minimum time for column formwork removal is $12 \mathrm{~h}$, while it can be modified if a retarder or accelerator is used $[7,8]$. It is understood that the removal of formworks is most times empirical while information on the strength may possibly come from material cast in parallel in small samples. However, a deterministic method to investigate the development of the mechanical properties of the cast concrete itself and enable safe and timely removal of formwork is not in place. In addition, the rate of hardening of concrete strongly depends on the environmental factors where the concrete is cast. Therefore, the removal time can vary between construction sites and even in the same construction site at different periods of the year. Monitoring concrete in the formworks gives the advantage of having real-time data about the state of the concrete and the formwork, consequently allowing engineering decisions about the removal time of each specific formwork.

The objective of the study is the experimental and numerical investigation of an ultrasonic monitoring technique to determine the time for safe removal of a site cylindrical formwork. This technique can be later connected to an acquisition and internet-of-things system to transmit real-time data about the state of the formworks measured by different sensors concerning not only the stiffness of concrete, but in general additional information about the health status of the formwork and its position. This study is based on experimental results on real-size composite construction formworks filled with fresh concrete where the ultrasound reflection as measured from the external surface supplies crucial information about the hardening state, and, thus, about potential demolding of the column.

\section{Ultrasound}

Ultrasound has proven very effective in monitoring the hardening of concrete [9-11]. The transit time between the pulser and the receiver can be easily measured leading to the ultrasonic pulse velocity and eventually to the elastic modulus, even allowing projections to the final compressive strength [12,13]. This is usually conducted in a special mold, where a relatively thin specimen of concrete is cast (a few $\mathrm{cm}$ maximum). However, one serious limitation is the attenuation of the fresh material that does not allow the measurement to be applied in thick members. Therefore, reflection measurements have also been utilized [14-16]. In this case, a pulser introduces an elastic wave into a buffer material that is in contact with concrete. The wave propagates until the interface between the buffer and the concrete. Then, one part of the energy is reflected, and it is captured by the receiver, while another part is transmitted into fresh concrete (see Figure 1a). The ratio between the transmitted and the reflected amplitude depends on the "reflection coefficient, $R$ " [17]. R is defined by the mismatch of acoustic impedances $Z_{1}$ and $Z_{2}$ of the two media (buffer and concrete respectively), as seen in Equation (1):

$$
R=\frac{Z_{2}-Z_{1}}{Z_{2}+Z_{1}}
$$

where the impedance, $\mathrm{Z}$ for any material is given by

$$
\mathrm{Z}_{i}=\rho_{i} \cdot \mathrm{C}_{i}
$$

In Equation (2), $\rho$ is the density and $C$ is the wave velocity of each material.

When concrete is fresh, its impedance is low because of the low pulse velocity, in the order of $500 \mathrm{~m} / \mathrm{s}$ or less $[9,10]$. Therefore, initially a quite strong reflection coefficient is expected. Gradually, as concrete hardens and the pulse velocity increases (the final could overpass $4000 \mathrm{~m} / \mathrm{s}$ ), concrete impedance rises towards the one of the buffer material or even higher, depending also on the impedance of the buffer itself. This change in impedance is 
monitored by the change of the reflected wave that is acquired by the receiver. A typical reflection setup for monitoring of concrete curing can be seen in Figure 1a.

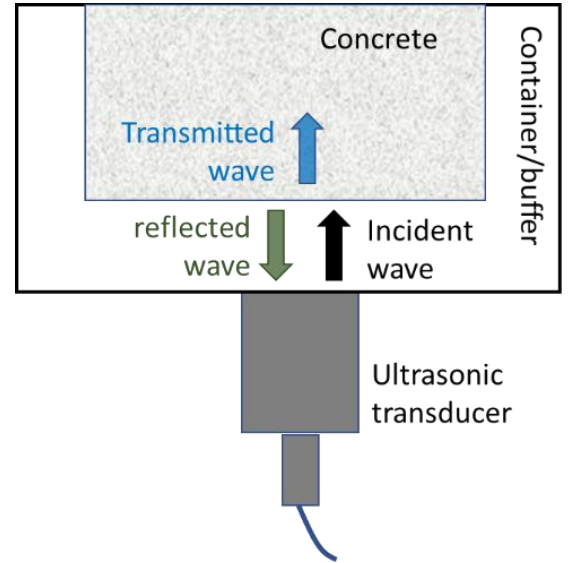

(a)

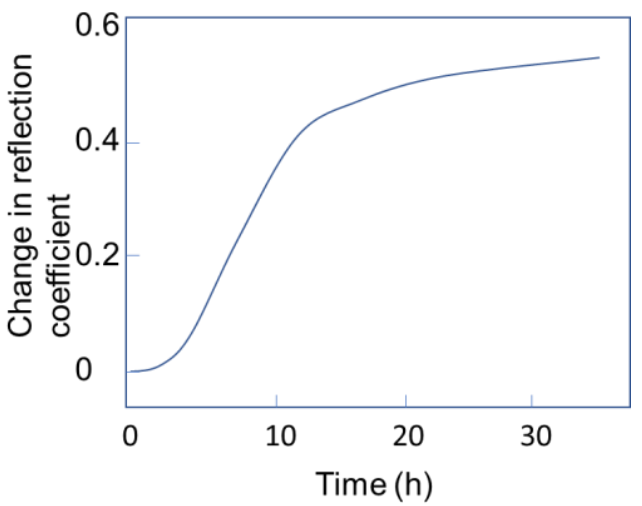

(b)

Figure 1. (a) Typical setup for ultrasound reflection measurement of concrete hydration, and (b) typical result of reflection change during hydration, inspired by [18].

This technique has been used in literature producing adequate results for monitoring of hardening. In most cases, the reflection coefficient development resembles the actual $\mathrm{S}$-shaped hydration curve as seen in Figure $1 \mathrm{~b}$ and is well correlated to the development of strength [18]. The choice of the buffer material is of paramount importance as pointed out in literature $[14,19]$. If a very stiff buffer is used, then its impedance would always be much higher than the one of concrete (even hardened) limiting the sensitivity of characterization. Setting time of cement pastes and concretes has been determined by high-sensitive, low-impedance buffers such as polymethyl methacrylate (PMMA) [20] and high impact polystyrene (HIPS) [14].

While an S-shaped reflection curve such as Figure $1 \mathrm{~b}$ allows the global monitoring of the hydration, it does not provide an unambiguous point of reference when the demolding should be conducted. To highlight the adequate moment, in this work the buffer material was suitably "engineered" and, specifically, it was designed so that its mechanical impedance matches the necessary impedance of concrete for safe demolding. This allows demolding when the reflection, as monitored by the receiver, drops to zero or a minimum point. When the impedances of the two media are similar, in theory, no reflection is expected $(R=0)$ and the transmission coefficient should be equal to 1 . Practically, this means that the reflected wave amplitude will undergo a minimum at that point, see Figure 2. As the concrete continues to harden, its impedance will overpass the one of the buffer, and the reflection coefficient will start rising again in absolute value. This way the characteristic minimum point in the reflection amplitude vs. monitoring time curve, will allow easier determination of the safe time for demolding. It can be highlighted at this point that similar behavior (e.g., minimum of the reflection curve) has been documented in literature [21,22]. In [22] the buffer was acrylic glass, showing higher impedance than fresh concrete and lower than hardened concrete. The "wave reflection factor" reached a minimum (close to but not equal to zero) and characteristic points of the curve were correlated to initial and final setting points, implying that the buffer (acrylic glass) was selected aiming at final setting determination. Although final setting is a key point in the hydration of cement and is useful in certain material-related studies, it does not practically guarantee the loadbearing capacity against construction weight or self-weight. Therefore, in this case the impedance of the buffer was targeted to be equal to the impedance of concrete when it is safe to be demolded, or specifically, when it exhibits a Young's modulus E of $5 \mathrm{GPa}$. This is the stiffness value that is considered the prerequisite for concrete column demolding in practical applications in cooperation with the industrial partner. As will be seen later, at this moment of stiffness development, the compressive strength of concrete is already above 
$7 \mathrm{MPa}$. Still, it is important to mention that the stiffness of the buffer can be manipulated to accommodate any possible minimum stiffness requirement or to meet other impedance criteria depending on the application. Therefore, knowing the density $\rho$, of the specific concrete mix (approximately $2500 \mathrm{~kg} / \mathrm{m}^{3}$ ), the ultrasonic pulse velocity $\mathrm{C}$ is calculated by Equation (3)

$$
C=\sqrt{\frac{E(1-v)}{\rho(1+v)(1-2 v)}}
$$

In Equation (3), $v$ is the Poisson's ratio which is not constant during setting. Experimentally, it has been measured at high values of more than 0.4 at very early age, while later it stabilizes to a value around 0.2 depending on the mix. In the specific case, the value of 0.3 was selected based on [12] since this was the Poisson's ratio value measured at approximately $10 \mathrm{~h}$ after mixing, the eventual time when demolding is proposed for the specific mix in the present study. The wave velocity is calculated to the value of $1660 \mathrm{~m} / \mathrm{s}$, according to Equation (3). Then the target impedance is calculated by Equation (2) to a value of 4.15 MRayl.

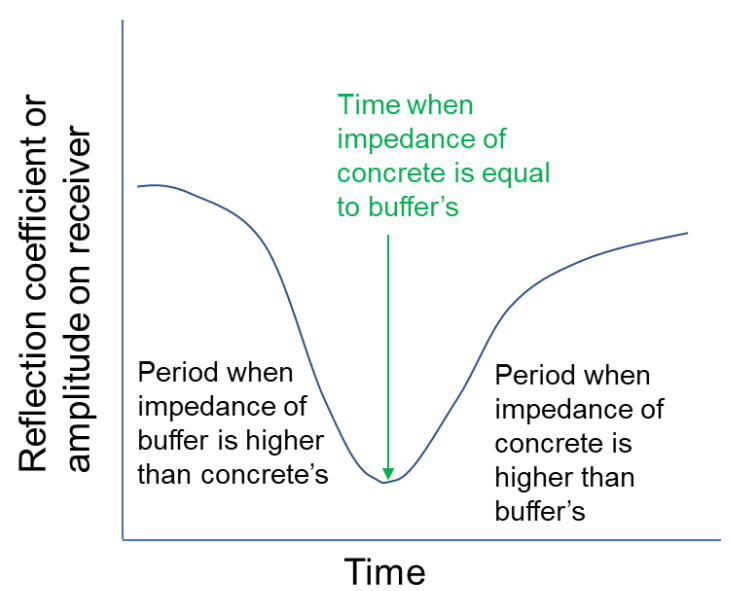

Figure 2. Expected reflection coefficient vs. concrete hydration time for a moderate stiffness buffer.

\section{Experimental Details}

The concrete mix had a water to cement ratio $(\mathrm{w} / \mathrm{c}) 0.5,380 \mathrm{~kg} / \mathrm{m}^{3}$ of cement I, $896 \mathrm{~kg} / \mathrm{m}^{3}$ large aggregates $(7-14 \mathrm{~mm}), 896 \mathrm{~kg} / \mathrm{m}^{3}$ small aggregates and $482 \mathrm{~kg} / \mathrm{m}^{3}$ sand. The density of fresh concrete was $2500 \mathrm{~kg} / \mathrm{m}^{3}$ and as stated previously the targeted impedance of safe-to-demold concrete was 4.15 MRayl. Different epoxy specimens were manufactured until the desired impedance was achieved. Epoxy consists of AW136H (main component) with a density of $1300 \mathrm{~kg} / \mathrm{m}^{3}$, and the hardener HY994 with a density of $930 \mathrm{~kg} / \mathrm{m}^{3}$. The proportion between them in mixing is $1 / 0.4$ and hardening comes at $2 \mathrm{~h}$. In order to increase the stiffness and density of the epoxy to match the desired value of impedance, the amount of Cristobalite sand (density $2330 \mathrm{~kg} / \mathrm{m}^{3}$ ) was increased in the mix. Eventually, a mix was selected exhibiting a density of $1652 \mathrm{~kg} / \mathrm{m}^{3}$ and a UPV was $2508 \mathrm{~m} / \mathrm{s}$ when the epoxy was hardened (measured in $24 \mathrm{~h}$ ) after mixing of the constituents. This resulted in the impedance of 4.14 MRayl. The UPV was measured by a standardized velocity meter at $54 \mathrm{kHz}$. The epoxy was cast directly on the formwork (and initially on the formwork model, as shown in Figure 3a) in a horizontal position, ensuring acoustic coupling between the buffer and the formwork. 


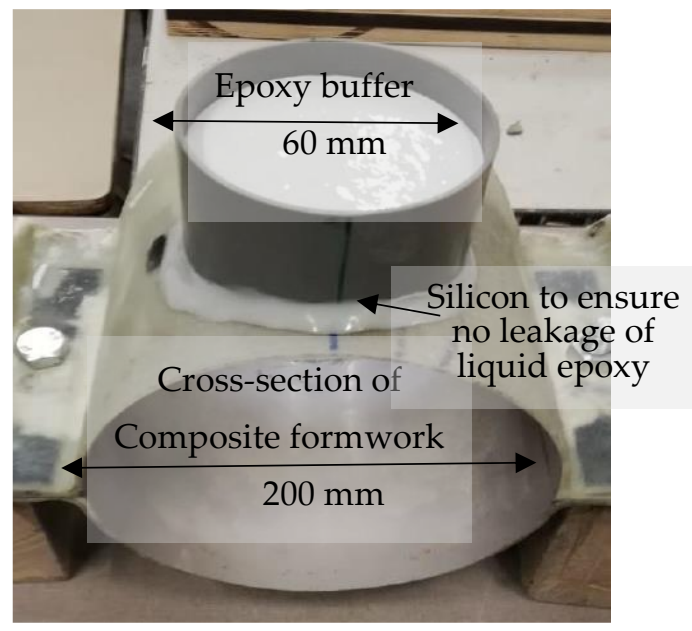

(a)

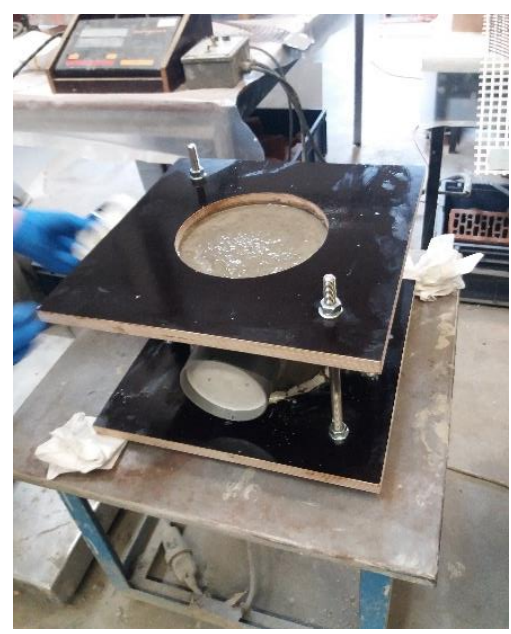

(b)

Figure 3. (a) Casting of the epoxy buffer on the formwork model on a horizontal position, and (b) concrete cast in the formwork of (a). The two wooden plates in (b) were used to control leakage.

Two concrete specimens were monitored. The first was a short section of the formwork (height of $300 \mathrm{~mm}$, internal diameter of $200 \mathrm{~mm}$ ) see Figure 3a,b, where it is filled with fresh concrete. Later, the real scale formwork was tested, as shown in Figure 4a,b. It has a height of $3 \mathrm{~m}$ and the same diameter of $200 \mathrm{~mm}$. The actual material of the formwork was glass-epoxy composite with a thickness of $3 \mathrm{~mm}$ and other properties are discussed in the simulation section.

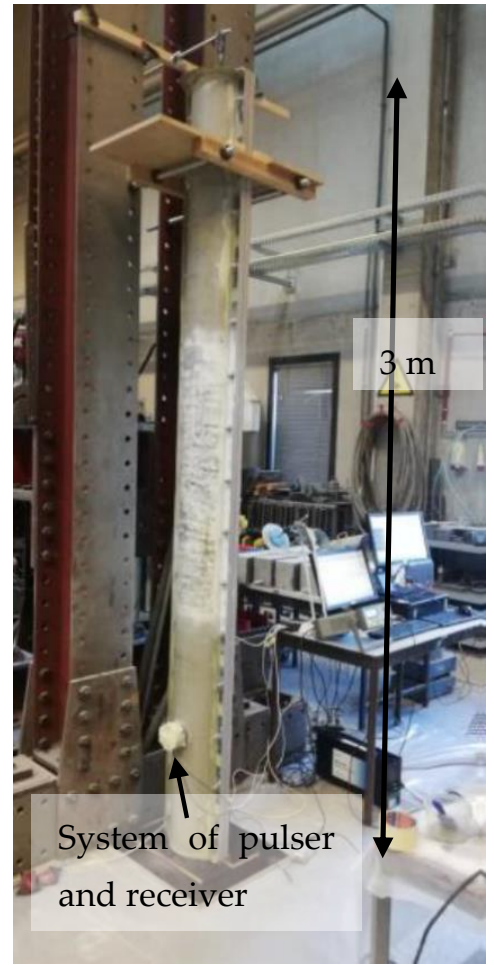

(a)

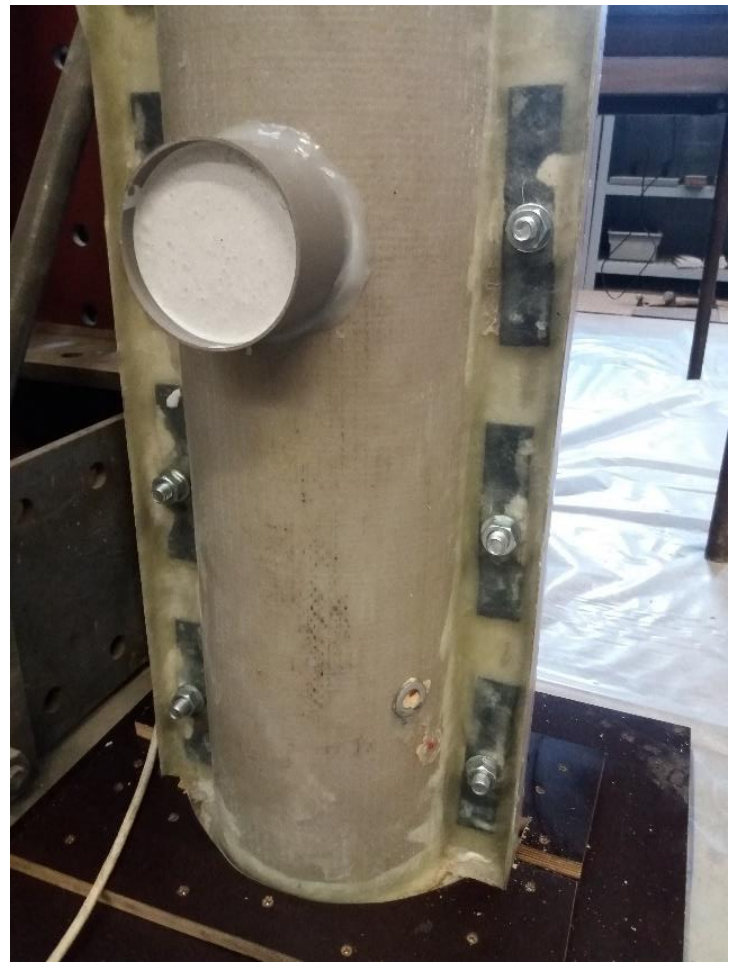

(b)

Figure 4. (a) The glass-epoxy composite formwork, and (b) closeup on the buffer cast in place where the two sensors will be placed.

The pair of pulser and receiver was attached at a distance of $50 \mathrm{~mm}$ from each other onto the epoxy buffer with silicone grease and covered with tape for stability, thus not 
allowing for a direct photograph. To demonstrate the detail of the sensors, they are included in Figure 5 featuring a preparatory experiment on a similar reflection mode. The two sensors were resonant at $150 \mathrm{kHz}$ (R15 of Mistras Group). The electric pulse from the wave function generator 3322A was fed to the one acting as pulser and was one cycle of $150 \mathrm{kHz}$ with an amplitude of $5 \mathrm{~V}$ every $3 \mathrm{~min}$. The waveform recorded by the other sensor was pre-amplified by $40 \mathrm{~dB}$, digitized at $10 \mathrm{MHz}$ and stored in a micro-II system of Mistras Group.

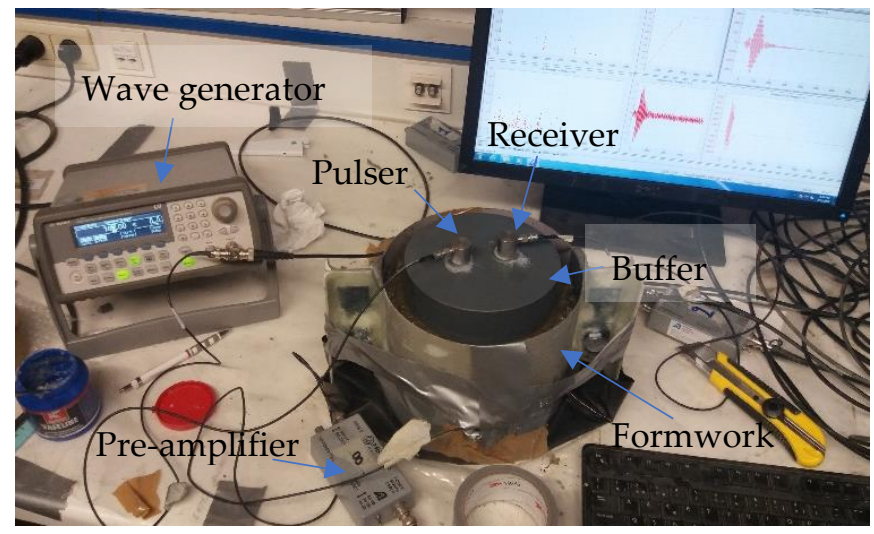

Figure 5. Pulser-receiver pair on a preliminary experiment.

\section{Results}

Figure 6 shows indicative waveforms at different times after casting, specifically, $3 \mathrm{~h}$, $10 \mathrm{~h}$ and $14 \mathrm{~h}$. The recorded waveform certainly includes the reflection from the interphase, but simultaneously carries other contributions, such as the surface wave travelling directly from the pulser to the receiver on the external side of the buffer, other reflections from the boundaries of the cylindrical buffer and, certainly, the resonant behavior of the sensor. The combination of the resonant behavior and the relatively low frequency does not allow accurate separation of the different contributions within the waveform and this is the reason that numerical simulations are also discussed later on. The major contribution comes after $50 \mu$ s being in agreement with the expected wave reflection coming from the interface considering the buffer thickness of $50 \mathrm{~mm}$ and the buffer UPV of $2500 \mathrm{~m} / \mathrm{s}$. Another strong burst is exhibited between 100 and $150 \mu$ s, with a lower amplitude, presumably from the 2nd reflection. The amplitude of these bursts is not constant with time. At $9 \mathrm{~h}$ (Figure 6b) both bursts seem to obtain a lower value than at $3 \mathrm{~h}$ (Figure 6a) and at $12 \mathrm{~h}$ (Figure 6c). Specifically, the 2nd burst after $100 \mu$ s stands at approximately $1.55 \mathrm{~V}$ (peak to peak) at $3 \mathrm{~h}$, see Figure 6a. At $9 \mathrm{~h}$ it is lower at about $1.32 \mathrm{~V}$ (Figure $6 \mathrm{~b}$ ). Later at $12 \mathrm{~h}$, it is again higher reaching approximately $1.69 \mathrm{~V}$ (Figure 6c). For later times it reaches an amplitude higher than $2 \mathrm{~V}$. Therefore, the hardening of the concrete itself without any other change in the setup plays a very significant role and influences the amplitude of the received signal. Other wave components, such as the direct Rayleigh, or reflections from the cylindrical boundary, are not expected to change as they are not influenced by the hardening of concrete; this is why the contribution until almost $50 \mu \mathrm{s}$ is identical to all waveforms. Therefore, the fluctuation of the amplitude with time can be safely attributed to the impedance changes in the hardening medium. It is again noted that even when the impedances of the buffer and concrete are equal, still the receiving transducer will record a certain level of amplitude due to the different aforementioned contributions; therefore, the point of interest is when the amplitude presents a minimum and not absolutely zero. 


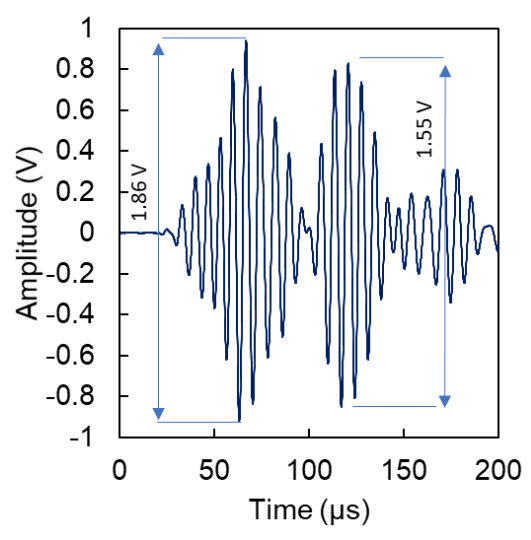

(a)

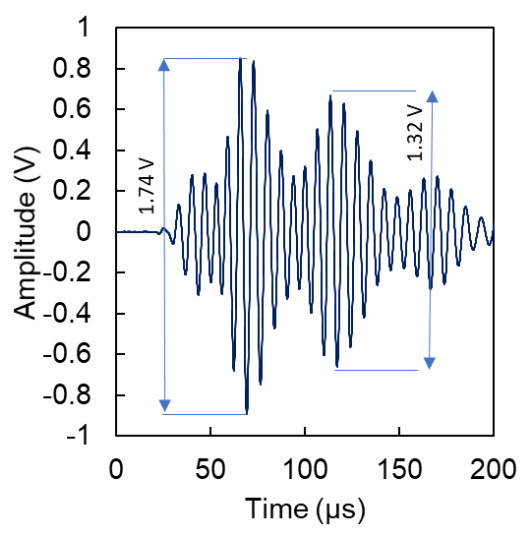

(b)

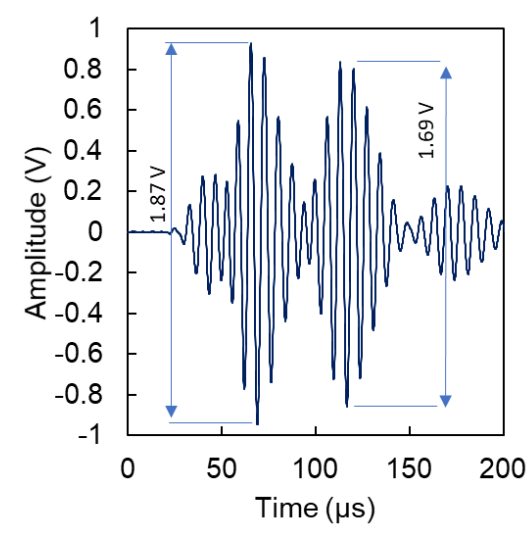

(c)

Figure 6. Receiver waveforms at three different times after casting (a) $3 \mathrm{~h}$, (b) $9 \mathrm{~h}$ and (c) $12 \mathrm{~h}$.

Figure 7a shows the receiver's peak amplitude (2nd burst between 100 and $150 \mu \mathrm{s}$ ) history for the case of the short model specimen (a) and the $3 \mathrm{~m}$ real-sized formwork (b). The curve of (a) shows that at $5 \mathrm{~h}$ after casting, the amplitude of the reflected wave started to decrease until it reached a minimum at approximately $10 \mathrm{~h}$. This point indicates that the impedance of the buffer material was very close to the impedance of the concrete at that time. After $10 \mathrm{~h}$, the concrete continued to gain stiffness and its impedance exceeded that of the buffer material resulting in a higher reflection again.

Moving to the real-scale formwork, the corresponding results are depicted in Figure $7 \mathrm{~b}$. A similar trend is seen when at approximately $9-10 \mathrm{~h}$ after casting, the receiver's amplitude undergoes a local minimum. This validates the initial result that this is the time when concrete obtains the impedance of 4.15 MRayl similar to the epoxy of the buffer, and the Young's modulus of $5 \mathrm{GPa}$.

Other smaller fluctuations in the amplitude curve are also observed, without a clear explanation, such as the initial increase of the received amplitude between 0 and $4 \mathrm{~h}$ in Figure 7a. These transient fluctuations may be due to changes in the local composition of the material behind the point of measurement (settlement of the material, air, water and aggregate mobility). However, both monitoring cases point to the time between $9-10 \mathrm{~h}$ as the period of minimum reflection and thus equal impedance between buffer and hardening concrete.

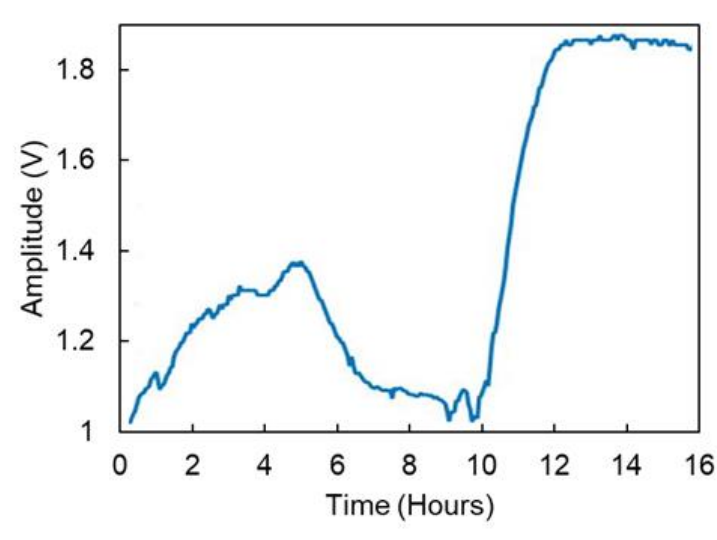

(a)

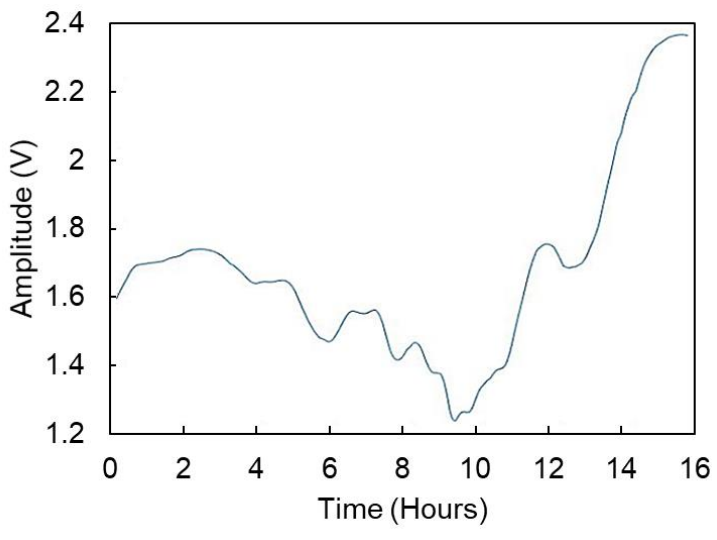

(b)

Figure 7. Received amplitude vs. time after casting for (a) short cross-section formwork experiment, and $(\mathbf{b})$ real-size formwork. 


\section{Numerical Simulations}

In order to increase the understanding of the phenomenon and validate the explanation of the results, numerical simulations were also conducted. A certain issue that deserved specific attention is that in the experiment, between the buffer material and concrete a third material is present (glass polyester composite of the formwork). Even though it is much thinner $(3 \mathrm{~mm})$ than the buffer $(50 \mathrm{~mm})$ and concrete column (diameter $200 \mathrm{~mm})$, and although its properties do not differ much from the buffer, it might still exercise a strong influence, and this cannot be simply assessed by Equation (1). Therefore, the exact cross-section of the specimen was modeled with the material of the formwork.

Numerical simulations were conducted with a commercially available software Wave2000 [23]. It computes displacement vectors by solving 2D elastic wave equations using a method of finite differences. The specific acoustic equation that is simulated is:

$$
\rho \frac{\theta^{2} u}{\theta t^{2}}=\left(\mu+\eta \frac{\theta}{\theta t}\right) \nabla^{2} u+\left(\lambda+\mu+\varphi \frac{\theta}{\theta t}+\frac{n}{3} \frac{\theta}{\theta t}\right) \nabla(\nabla u),
$$

where $u$ is the displacement vector (consisting of two $u_{x}$ and $u_{y}$ components perpendicular to each other), $\rho$ is the density $\left(\mathrm{kg} / \mathrm{m}^{3}\right), \lambda$ and $\mu$ are the first and second Lamé constants (Pa), $\eta$ and $\varphi$ are the "shear" and "bulk" viscosity (Pa.s) and $t$ is time (s) [23].

The model contains three media with distinct sets of material properties. The buffer material has a minimum width of $50 \mathrm{~mm}$ (at the center). It is placed adjacent to the formwork from one side, and from the other side, a source and a receiver transducer are placed with a distance of $50 \mathrm{~mm}$ between them (see Figure 8). The concrete is placed in a semi-circle with a diameter of $200 \mathrm{~mm}$. An infinite boundary condition is used on the right side since only the first reflection at the interface between the buffer material and the concrete is of interest. The resolution in time was $0.05 \mu \mathrm{s}$, sufficiently shorter than the period of the wave even for the highest frequency tested $(1 \mathrm{MHz})$. Therefore, each cycle was represented by as many as 20 points, according to relevant recommendations in literature [24]. Similarly, the space resolution was set to $0.15 \mathrm{~mm}$, which is much smaller than the wavelength considering the wave speed of the buffer material (approximately $3 \mathrm{~mm}$ for $1 \mathrm{MHz}$ ).
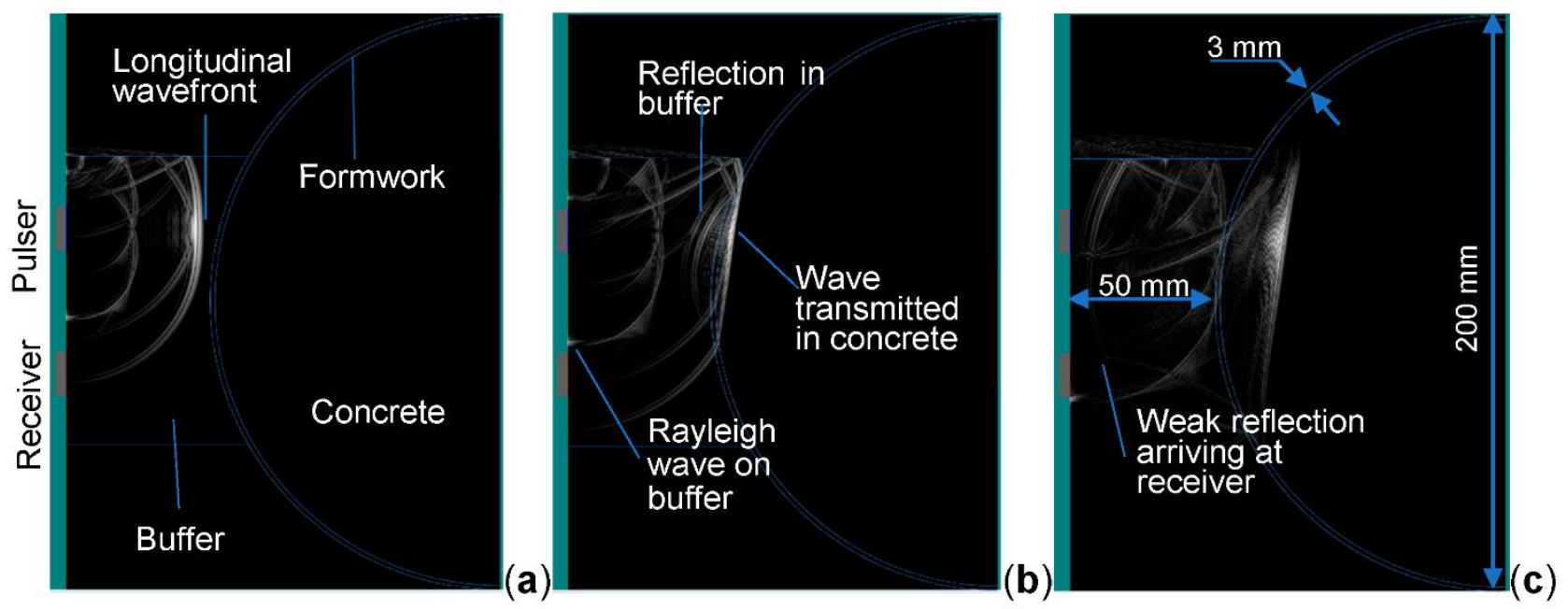

Figure 8. Numerical displacement field (a) $20 \mu \mathrm{s}$, (b) $30 \mu \mathrm{s}$ and (c) $40 \mu \mathrm{s}$ after excitation of $1 \mathrm{MHz}$ for concrete properties \#1 (fresh concrete).

To simulate the development of stiffness in the fresh concrete, several stages of the concrete evolution were defined to account for the ongoing hydration process (see Table 1). The properties of the buffer material are taken similar to the experimental. The formwork is made of fiber glass with a polyester matrix and has a density of $1800 \mathrm{~kg} / \mathrm{m}^{3}$. The ultrasonic 
speed $C_{P}$ was measured using the ultrasonic velocity meter to the value of $2000 \mathrm{~m} / \mathrm{s}$ through the thickness of the material.

The material properties are illustrated in Table 1.

Table 1. Properties of materials used in numerical simulation.

\begin{tabular}{|c|c|c|c|}
\hline Material & Wave Speed $C_{P}(\mathrm{~m} / \mathrm{s})$ & Density, $\rho\left(\mathrm{kg} / \mathrm{m}^{3}\right)$ & Impedance, Z (MRayl) \\
\hline Buffer material & 2508 & 1652 & 4.14 \\
\hline Formwork & 2000 & 1800 & 3.60 \\
\hline Concrete 1 (fresh) & 1095 & 2500 & 2.74 \\
\hline Concrete 2 & 1341 & 2500 & 3.35 \\
\hline Concrete 3 (similar impedance to buffer) & 1673 & 2500 & 4.18 \\
\hline Concrete 4 & 1788 & 2500 & 4.47 \\
\hline Concrete 5 & 2097 & 2500 & 5.24 \\
\hline Concrete 6 & 2300 & 2500 & 5.75 \\
\hline Concrete 7 & 2683 & 2500 & 6.71 \\
\hline Concrete 8 & 3098 & 2500 & 7.75 \\
\hline Concrete 9 & 3633 & 2500 & 9.08 \\
\hline Concrete 10 (hardened) & 4049 & 2500 & 10.12 \\
\hline
\end{tabular}

It is noted that the impedance of the formwork is not far apart from the one of the buffer.

The source or pulser has a size of $15 \mathrm{~mm}$ which is equivalent to the diameter of the transducers used in the experiments. The displacement source wave function is defined as a sinusoidal cycle that is excited vertical to the surface, and therefore with horizontal direction in Figure 8a. Since the simulations are in the linear regime, the unit of the amplitude does not play a role. If one assumes that the excitation is in $\mathrm{nm}$, this is the unit of the amplitude of the receiver that is presented. While the experimental frequency was $150 \mathrm{kHz}$, the frequency of $1 \mathrm{MHz}$, was also simulated. The reason is that higher frequencies correspond to shorter periods and thus sharper signals, allowing easier differentiation of possible reflections and different wave modes, as evidenced in the snapshots of Figure 8, and later in the waveforms.

Figure 8a shows the displacement field approximately $20 \mu$ s after the excitation for the case of fresh concrete ("concrete 1" in Table 1). The longitudinal wavefront propagates in the depth of the buffer towards concrete as well as on the surface reaching the receiver, while the Rayleigh wave follows. Figure $8 \mathrm{~b}$, shows the field after approximately $30 \mu \mathrm{s}$. Now part of the wave has already been transmitted into the concrete while the reflection from the interface is also visible. In Figure $8 \mathrm{c}$ the reflection is close to the receiver.

Figure 9 shows the corresponding displacement fields for concrete hardening stage \#3. The point of interest is that the reflection is much weaker, and it is essentially negligible in Figure $9 \mathrm{c}$ when it is supposed to reach the receiver. Finally, for concrete \#10, corresponding to hardened conditions according to Table 1 , the reflection becomes, again, visible and even stronger (see Figure 10b,c).

Indicative waveforms as recorded by the sensor for three different stiffness values of concrete can be seen in Figure 11a. One corresponds to fresh concrete (\#1 in Table 1), the second to an intermediate stiffness (\#3) and the last to fully hardened concrete (\#10).

Correspondingly to the experimental waveforms, all three numerical waveforms share exactly the same initial part (until about $40 \mu \mathrm{s}$ ) because of the longitudinal wave travelling on the surface (visible at $15 \mu \mathrm{s}$ ) and the strong Rayleigh portion between $27 \mu \mathrm{s}$ and $40 \mu \mathrm{s}$. The Rayleigh part does not resemble the single cycle of the excitation because of the "aperture effect" [25]. The Rayleigh wavelength for $1 \mathrm{MHz}$ is less than $2 \mathrm{~mm}$, much smaller than the sensor size of $15 \mathrm{~mm}$. Therefore, while the whole Rayleigh portion is within the receiver boundaries, positive and negative phases are essentially eliminated allowing indications only when it enters (approximately at $27 \mu \mathrm{s})$ and when it exits $(40 \mu \mathrm{s})$ the physical size of the sensor. The differentiation between the three waveforms comes after $40 \mu \mathrm{s}$, when the longitudinal reflection from the buffer arrives. For the case \#1 (red line, 
fresh concrete) a reflection is visible because of the impedance mismatch at the interface, as aforementioned. For case \#3 (black line) however, this cycle is reasonably suppressed because of similar impedances for concrete and buffer (both approximately 4.15 MRayl). For the last case of hardened concrete (\#10, blue line) a reflection is again obvious and even stronger than case \#1 while now the phase of the cycle is reversed. This is because the concrete has become stiffer than the buffer and therefore, the reflection coefficient mathematically obtains the opposite sign [17]. By using the high frequency of $1 \mathrm{MHz}$, the reflections can be detected showing in the fresh state a weak reflection, while for the next stage (\#3) the reflection can hardly be identified. Later, for concrete stage \#10, the reflection amplitude climbs up to a value 5 to 6 times higher than the minimum of case \#3, allowing clear observation, as seen in Figure $11 \mathrm{~b}$ that focuses on the reflection arrival.
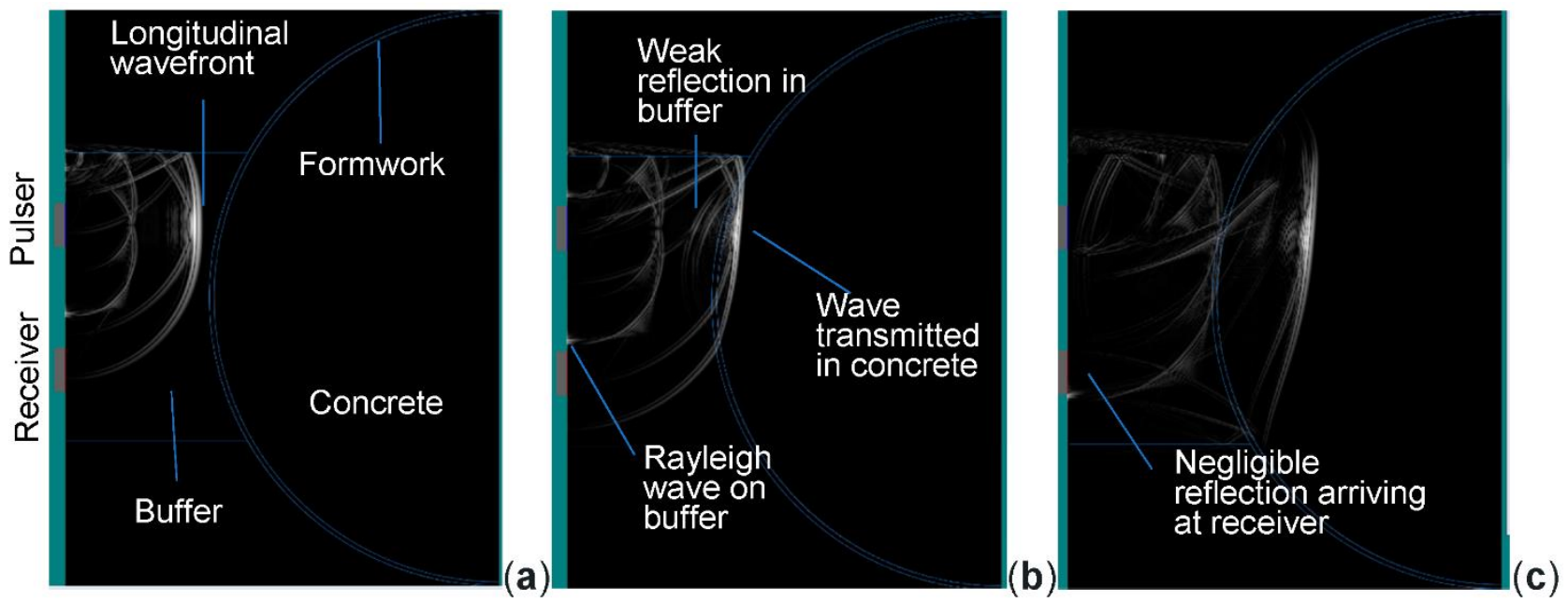

Figure 9. Numerical displacement field (a) $20 \mu \mathrm{s}$, (b) $30 \mu \mathrm{s}$ and (c) $40 \mu$ s after excitation of $1 \mathrm{MHz}$ for concrete properties \#3 (impedance similar to buffer).
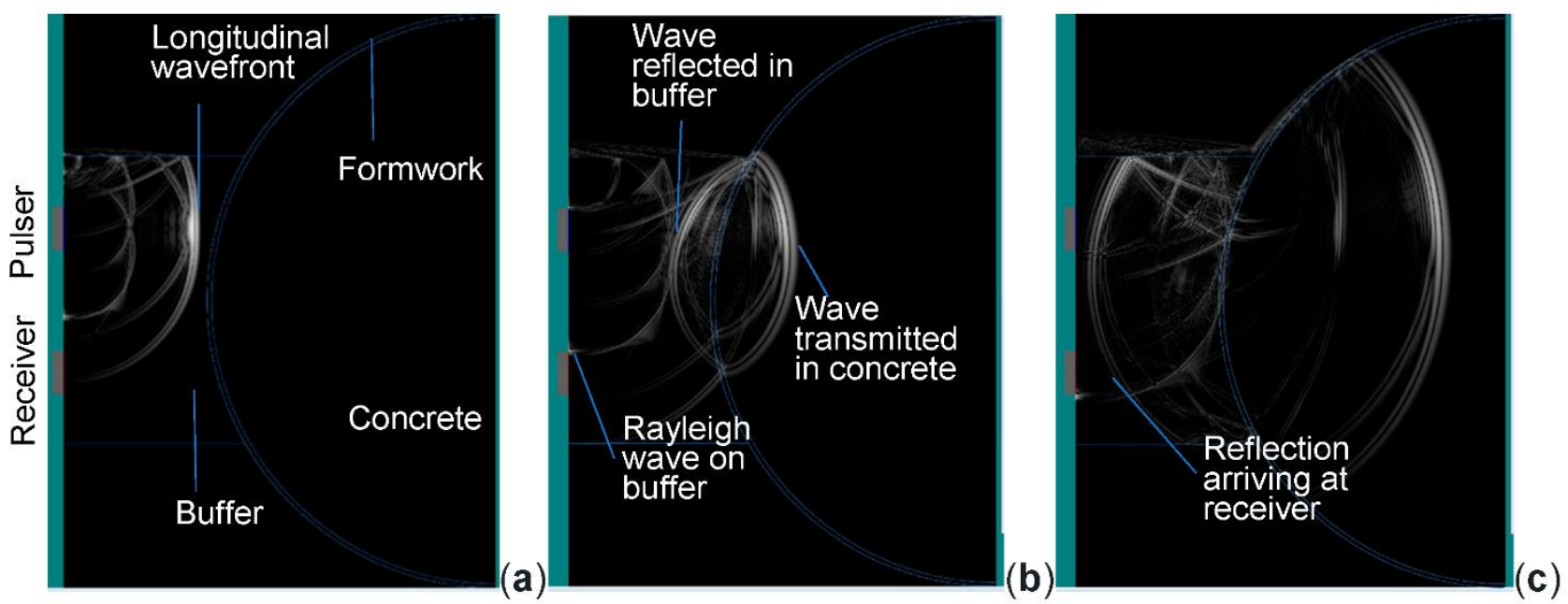

Figure 10. Numerical displacement field (a) $20 \mu \mathrm{s}$, (b) $30 \mu \mathrm{s}$ and (c) $40 \mu \mathrm{s}$ after excitation of $1 \mathrm{MHz}$ for concrete properties \#10 (hardened).

Figure 12, shows the corresponding waveforms for the excitation of $150 \mathrm{kHz}$. All waveforms share, again, the same content up to approximately $40 \mu \mathrm{s}$. Despite that, in this case, the period of the cycles is longer than the frequency of $1 \mathrm{MHz}$, strong changes are still noted in the reflection window, with the hardened concrete exhibiting the highest amplitude at the time when the reflection is expected. 


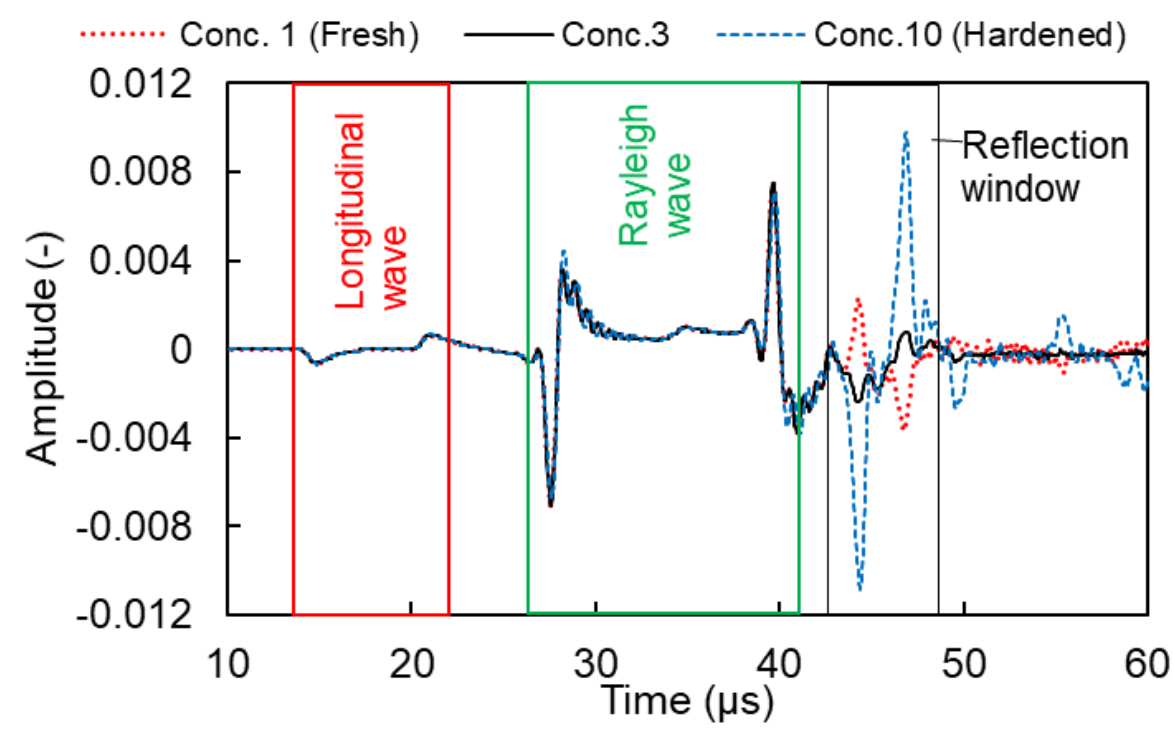

(a)

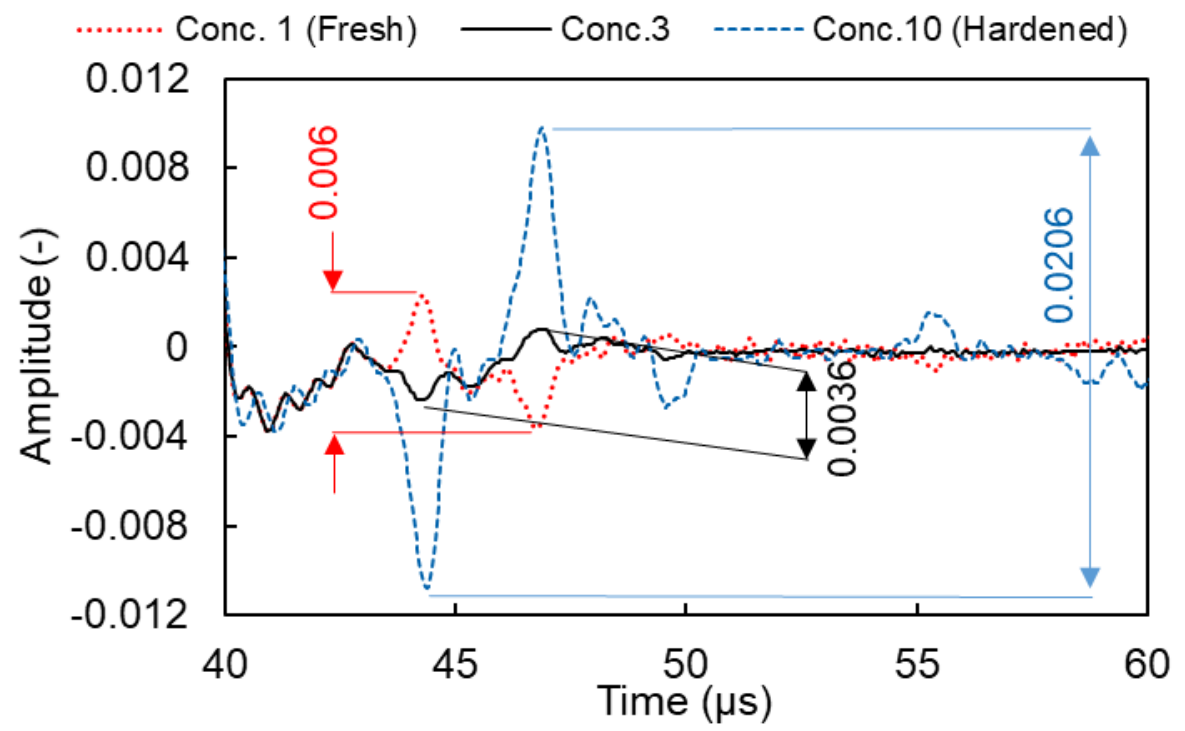

(b)

Figure 11. (a) Receiver waveforms for different concrete stages and (b) closeup of the "reflection window" of (a). The excitation is one cycle of $1 \mathrm{MHz}$ and the number of concrete hardening stage refers to Table 1.

Measuring the amplitude of the waveform between 40 and $50 \mu$ s for each of the concrete stages, one can clearly see the effect of hardening (Figure 13). There, the amplitude for different concrete stages shows that initially, the reflection decreases until it reaches a minimum at stage \#3. Then the trend is reversed, and the reflection amplitude increases until the final set of properties checked (hardened concrete with UPV above $4000 \mathrm{~m} / \mathrm{s}$ ). The trend is similar to the experimental and validates the conclusion that with the proper selection of the buffer material, a characteristic point (a minimum) in the reflection history can be easily obtained indicating when removal of the formwork is due. 


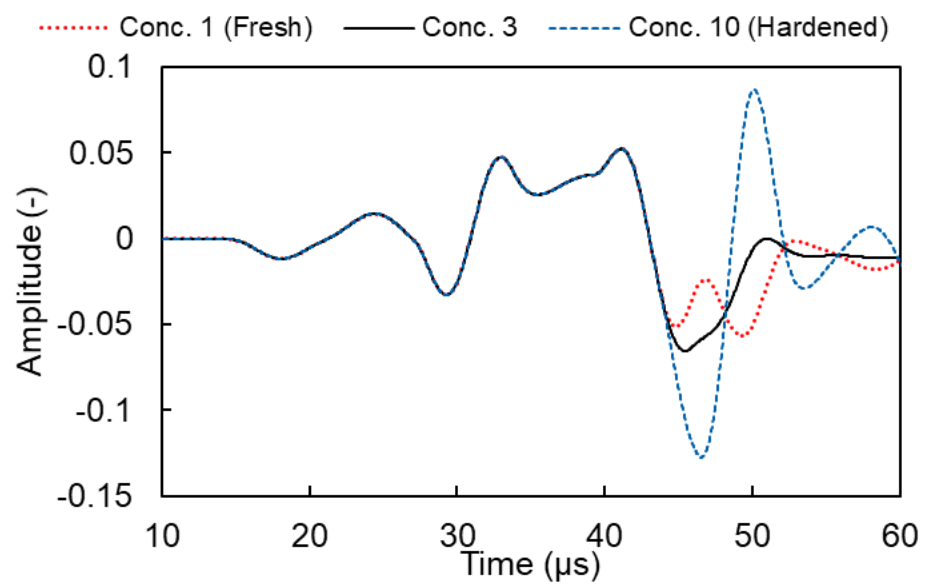

Figure 12. Receiver waveforms for different concrete stages. The excitation is one cycle of $150 \mathrm{kHz}$ and the number of concrete stage refers to Table 1.

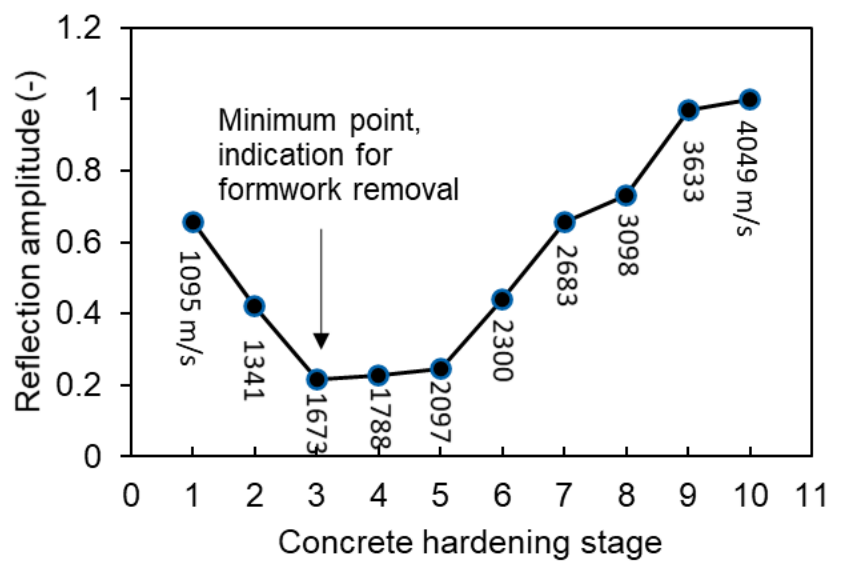

Figure 13. Numerical reflection amplitude for different concrete hardening stages. The values below each point correspond to the wave speed $(\mathrm{m} / \mathrm{s})$ of concrete used for the simulation.

\section{Discussion}

In order to check the strength, standard cubic specimens of $150 \mathrm{~mm}$ side were cast from the same concrete mix and maintained for mechanical test of the compressive strength at early ages. As seen in Figure 14, at $6 \mathrm{~h}$, hardening was not yet exhibited as the compressive strength was less than $1 \mathrm{MPa}$. At $18 \mathrm{~h}$, the strength had already increased to $20.4 \mathrm{MPa}$, while the development continued but with lower rate, reaching almost $40 \mathrm{MPa}$ at $48 \mathrm{~h}$. Based on these data, it can be extrapolated that the strength at the time of $10 \mathrm{~h}$, when the target stiffness was reached according to the reflection measurement, was approximately 7-8 MPa.

Concerning the ultrasonic application, and although the results are sufficient to indicate the minimum point, it is expected that moderately higher frequencies could provide an even clearer experimental curve, as the separation between the different modes would enhance the focus on the reflection. Another strategy would be to focus on the total energy of the received waveform. While the rest of the modes stay unaltered, the reflection is the wave component that is influenced by the impedance mismatch. When the impedances of the media are similar, the reflection is at its minimum, lowering the total amount of energy received back at the sensor allowing again the selection of the de-molding moment.

One point of potential concern is that the reflection measurement corresponds to the interface, so it is representative of the hardening state close to the surface, which may be slightly different than the bulk of the concrete. Another point is that the Poisson's ratio may be quite influential in the derivation of the elasticity modulus through the pulse velocity. 
Poisson's ratio can be given by reference studies, or even measured through monitoring of longitudinal and shear (or Rayleigh) waves.

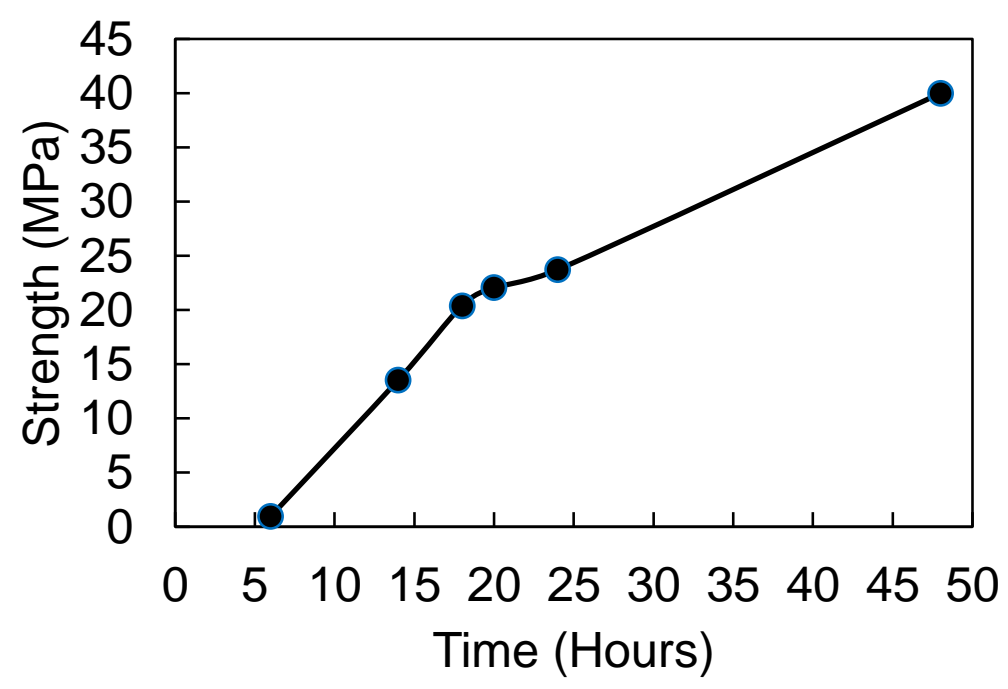

Figure 14. Compressive strength vs. early age of concrete cubes.

\section{Conclusions}

The aforementioned experimental and numerical results indicate that ultrasound reflection is suitable to measure the hardening in large concrete elements through the formwork. In addition, it allows to pinpoint the moment when the material has obtained the necessary stiffness to be safely demolded. The reason is that the reflection received through a buffer material is sensitive to the mechanical impedance of concrete; initially it is lower than the buffer material, resulting in a noticeable reflection, while later it increases, inevitably equaling for a short period of time that of the buffer, before surpassing it. That milestone period is characterized, therefore, by a local minimum in the reflection vs. time curve in the experiment (or hardening stage in simulations) and makes the realization of the moment that concrete has developed the necessary stiffness possible. It is important to state, that as also the case in this study, the buffer material can be suitably engineered in order to produce the minimum reflection at the proper stiffness of concrete based on the application (e.g., requirements for columns, beams and slabs may differ). In certain cases, the formwork alone could be used as buffer, provided that its thickness is longer than the wavelength allowing clear distinction of the reflection.

Author Contributions: Conceptualization, D.G.A. and O.R.; methodology, D.G.A. and O.R.; software, R.J. and N.O.; validation, O.R. and D.G.A.; formal analysis, N.O. and R.J.; investigation, R.J. and N.O.; data curation, R.J. and N.O.; writing—original draft preparation, D.G.A. and N.O.; writing-review and editing, O.R. and D.G.A.; visualization, R.J.; funding acquisition, D.G.A. and O.R. All authors have read and agreed to the published version of the manuscript.

Funding: This research was funded by FWO (Fonds Wetenschappelijk Onderzoek- Vlaanderen), grant number G.0337.19.N.

Institutional Review Board Statement: Not applicable.

Informed Consent Statement: Not applicable.

Data Availability Statement: The data of this study is available upon request, where justified, by email to the corresponding author. 


\begin{abstract}
Acknowledgments: The financial support of FWO (Fonds Wetenschappelijk Onderzoek-Vlaanderen), project number G.0337.19.N. is gratefully acknowledged. The contribution of Divyanshu Sharma in the mechanical tests of concrete is gratefully acknowledged.

Conflicts of Interest: The authors declare no conflict of interest. The funders had no role in the design of the study; in the collection, analyses, or interpretation of data; in the writing of the manuscript; or in the decision to publish the results.
\end{abstract}

\title{
References
}

1. Available online: https://timesofindia.indiatimes.com/city/goa/60-of-building-failures-are-due-to-formwork-collapse/ articleshow /47208321.cms (accessed on 18 January 2022).

2. Available online: https://theconstructor.org/building/formwork-shuttering/causes-formwork-failures/35478/ (accessed on 12 December 2021).

3. Anthony, W.R.; Stainer, P.J. Concrete high rises offer many cost advantages. Concr. Constr. 1988, 33, $453-456$.

4. Rudeli, N.; Santilli, A. Tiempos de desencofrado de elementos verticales de hormigón armado. Mem. Investig. En Ing. 2014, 12, 45-55.

5. $\quad$ EN 1992-1-2. Eurocode 2: Design of Concrete Structures-Part 1-2, 1st ed.; BSi.R: Brussels, Belgium, 2004.

6. Mehta, P.K.; Monteiro, P.J. Concrete: Microstructure, Properties and Materials, 4th ed.; McGraw-Hill Education: New York, NY, USA, 2013.

7. ACI Committee 347. ACI 347-04: Guide to Formwork for Concrete. In Manual of Concrete Practice; ACI 347; American Concrete Institute (ACI): Farmington Hills, MI, USA, 2004.

8. ACI Committee 318. ACI 318-14: Building Code Requirements for Reinforced Concrete. In Manual of Concrete Practice; ACI 318; American Concrete Institute (ACI): Farmington Hills, MI, USA, 2014.

9. De Belie, N.; Grosse, C.; Kurz, J.; Reinhardt, H.-W. Ultrasound monitoring of the influence of different accelerating admixtures and cement types for shotcrete on setting and hardening behaviour. Cem. Concr. Res. 2005, 35, 2087-2094. [CrossRef]

10. Steger, L.; Blotevogel, S.; Frouin, L.; Patapy, C.; Cyr, M. Experimental evidence for the acceleration of slag hydration in blended cements by the addition of $\mathrm{CaCl}$ 2. Cem. Concr. Res. 2021, 149, 106558. [CrossRef]

11. Trtnik, G.; Gams, M. Recent advances of ultrasonic testing of cement based materials at early ages. Ultrasonics 2014, 54, 66-75. [CrossRef] [PubMed]

12. Abeele, K.V.D.; Desadeleer, W.; De Schutter, G.; Wevers, M. Active and passive monitoring of the early hydration process in concrete using linear and nonlinear acoustics. Cem. Concr. Res. 2009, 39, 426-432. [CrossRef]

13. Park, J.Y.; Yoon, Y.G.; Oh, T.K. Prediction of Concrete Strength with P-, S-, R-Wave Velocities by Support Vector Machine (SVM) and Artificial Neural Network (ANN). Appl. Sci. 2019, 9, 4053. [CrossRef]

14. Popovics, J.S.; Subramaniam, K.V.L. Review of Ultrasonic Wave Reflection Applied to Early-Age Concrete and Cementitious Materials. J. Nondestruct. Eval. 2014, 34, 1-12. [CrossRef]

15. Suraneni, P.; Struble, L.J.; Popovics, J.S.; Chung, C.-W. Set Time Measurements of Self-Compacting Pastes and Concretes Using Ultrasonic Wave Reflection. J. Mater. Civ. Eng. 2015, 27, 04014117. [CrossRef]

16. Trtnik, G.; Valic, M.I.; Turk, G. Measurement of setting process of cement pastes using non-destructive ultrasonic shear wave reflection technique. NDT E Int. 2013, 56, 65-75. [CrossRef]

17. Shull, P.J.; Bernard, R. Tittmann, Ultrasound, in Nondestructive Evaluation, Theory, Techniques, and Applications; Shull, P.J., Ed.; Marcel Dekker: New York, NY, USA, 2001; pp. 63-192.

18. Akkaya, Y.; Voigt, T.; Subramaniam, K.; Shah, S.P. Nondestructive measurement of concrete strength gain by an ultrasonic wave reflection method. Mater. Struct. 2003, 36, 507-514. [CrossRef]

19. Valič, M. Hydration of cementitious materials by pulse echo USWR: Method, apparatus and application examples. Cem. Concr. Res. 2000, 30, 1633-1640. [CrossRef]

20. Subramaniam, K.V.; Lee, J.; Christensen, B.J. Monitoring the setting behavior of cementitious materials using one-sided ultrasonic measurements. Cem. Concr. Res. 2005, 35, 850-857. [CrossRef]

21. Chung, C.-W.; Suraneni, P.; Popovics, J.S.; Struble, L.J. Using ultrasonic wave reflection to monitor false set of cement paste. Cem. Concr. Compos. 2017, 84, 10-18. [CrossRef]

22. Öztürk, T.; Kroggel, O.; Grübl, P.; Popovics, J. Improved ultrasonic wave reflection technique to monitor the setting of cementbased materials. NDT E Int. 2005, 39, 258-263. [CrossRef]

23. Wave2000 Plus-Software for Computational Ultrasonics. Cyberlogic. Available online: http://www.cyberlogic.org/wave2000. html (accessed on 16 January 2022).

24. Moser, F.; Jacobs, L.J.; Qu, J. Modeling elastic wave propagation in waveguides with the finite element method. NDT E Int. 1999, 32, 225-234. [CrossRef]

25. Ospitia, N.; Aggelis, D.G.; Lefever, G. Sensor Size Effect on Rayleigh Wave Velocity on Cementitious Surfaces. Sensors 2021, $21,6483$. [CrossRef] [PubMed] 